\title{
TRANSPIRAÇÃO DE ESPÉCIES TÍPICAS DO CERRADO MEDIDA POR TRANSPIRÔMETRO DE EQUILÍBRIO E PORÔMETRO
}

\author{
Cynthia Domingues de Souza ${ }^{1}$, Daiana Pereira Fernandes ${ }^{2}$, Michelle Rodrigues Barroso ${ }^{3}$, Tomás de Aquino Portes ${ }^{4}$
}

(recebido: 10 de junho de 2010; aceito: 30 de junho de 2011)

\begin{abstract}
RESUMO: Critérios ecofisiológicos precisam ser conhecidos para adoção de modelos eficientes de manejo florestal, uma vez que são estabelecidas relações entre fatores ambientais e respostas metabólicas das espécies. A transpiração é influenciada por vários fatores, inclusive, pela espécie florestal. Neste trabalho, propõe-se relacionar medidas de transpiração obtidas no "Transpirômetro de Equilíbrio" (Transpirômetro) e no "Porômetro de Estado de Estacionário" (Porômetro) para as seguintes espécies florestais: Ipê amarelo (Tabebuia serratifolia Nichols), Jatobá (Hymenaea stigonocarpa Mart. Ex Hayne), Bálsamo (Myroxilom balsamum Harms.), Eucalyptus camaldulensis Dehn. e E. citriodora Hook. O experimento foi instalado na casa de vegetação da Universidade Federal de Goiás. Consistiu de cinco tratamentos com quatro repetições em um delineamento inteiramente casualizado. E com duração de três meses. Diante dos resultados obtidos, pode-se notar que os valores de transpiração do Transpirômetro foram superiores aos do Porômetro para os eucaliptos, em todos os dias. Para jatobá e ipê, a transpiração medida no Transpirômetro foi menor do que o do Porômetro em pelo menos um dia. Quanto ao bálsamo, o valor foi semelhante em ambos os equipamentos no DJ 292. Essas diferenças se justificam uma vez que o Porômetro registra a transpiração instantânea na folha e o Transpirômetro quantifica da planta toda, sendo, portanto, uma medida cumulativa. As espécies estudadas apresentam diferentes respostas: os eucaliptos transpiram mais do que as nativas, sendo doze vezes mais do que bálsamo, sete a mais do que o ipê e seis vezes a transpiração do jatobá.
\end{abstract}

Palavras-chave: Ecofisiologia, espécies nativas, espécies exóticas.

\section{TRANSPIRATION OF SPECIES TYPICAL OF CERRADO AS MEASURED BY BALANCE TRANSPIROMETER AND BY POROMETER}

\begin{abstract}
Ecophysiological criteria need to be known in order to adopt effective forest management models, since through them relationships are established between environmental factors and metabolic responses of species. Transpiration is influenced by several factors, including the relevant species. This study aims to relate measurements of transpiration using a 'Balance State Transpirometer' (Transpirometer) and a 'Steady State Porometer'(Porometer) for the following forest species: Yellow Ipe (Tabebuia serratifolia Nichols), Jatoba (Hymenaea stigonocarpa Mart. Ex Hayne), Balsamo (Myroxilom balsamum Harms.), Eucalyptus camaldulensis Dehn. and E. citriodora Hook. The experiment was set up in the greenhouse of the Federal University of Goiás and consisted of five treatments with four replicates in a completely randomized design, over a period of three months. Results revealed that transpiration values provided by the Transpirometer were higher than those provided by the Porometer for the eucalyptuses, in all days. As for jatoba and ipe, the transpiration measured by the Transpirometer was lower than that measured by the Porometer in at least one day. And as for balsamo, the value measured was similar in both devices on JD 292. These differences are justified by the fact that the Porometer records leaf transpiration instantly while the Transpirometer quantifies transpiration by the entire plant and therefore is a cumulative measure. The species being studied had different response: the eucalyptuses transpire more than the native trees, namely twelve times more than balsamo, seven times more than ipe and six times as much as jatoba.
\end{abstract}

Key words: Ecophysiology, native species, exotic species.

\section{INTRODUÇÃO}

Um grande desafio mundial mobiliza os pesquisadores desse século: desenvolver tecnologias em todas as áreas produtivas que diminuam os impactos negativos sobre o planeta, notadamente quanto ao consumo racional de água doce.
Novos paradigmas de produção vêm sendo delineados para o aumento de produtividade com o menor consumo de água, adotando-se o princípio da ecoeficiência.

Assim, a ciência florestal brasileira atualmente tem entre as principais linhas de pesquisa, os trabalhos conduzidos nas áreas de modelos ecofisiológicos para

\footnotetext{
${ }^{1}$ Engenheira Florestal, Doutora em Produção Vegetal - Instituto Brasileiro do Meio Ambiente e dos Recursos Naturais Renovaveis/IBAMA Rua 229, no 95 - 74605-090 - Goiânia, GO - cynthiad.souza@hotmail.com

${ }^{2}$ Bióloga, Mestre em Biologia - Instituto de Ciências Biológicas - Universidade Federal de Goiás/UFG - Campus Samambaia - Saída para Nerópolis, Km 13 - Cx. P. 131 - 74001-970 - Goiânia, GO - dnanthera@hotmail.com

${ }^{3}$ Engenheira Agrônoma - Escola de agronomia - Universidade Federal de Goiás/UFG - Rodovia Goiânia / Nova Veneza, Km 0 - Cx. P. 131 4001-970-michelle_agro@hotmail.com

${ }^{4}$ Professor Doutor em Biologia Vegetal - Instituto de Ciências Biológicas - Universidade Federal de Goiás/UFG - Campus Samambaia - Saída para Nerópolis, Km 13 - Cx. P. 131 - 74001-970 - Goiânia, GO - portes@icb.ufg.br.
}

Cerne, Lavras, v. 17, n. 4, p. 509-515, out./dez. 2011 
nortear a produção florestal (PENTEADO, 2004; RODRIGUEZ et al., 2002).

Portanto, critérios ecofisiológicos das espécies arbóreas precisam ser conhecidos para a adoção de modelos eficientes de manejo florestal, uma vez que a ecofisiologia estabelece relações entre os fatores ambientais e os processos de respostas metabólicas das espécies (LARCHER, 2000).

A transpiração é influenciada por diversos fatores: clima, solo, idade das plantas, disponibilidade de água no solo e inclusive, pela espécie florestal. A transpiração intensifica-se com a diminuição da umidade relativa do ar e com o aumento da temperatura. O aquecimento da folha, em decorrência da forte radiação, também eleva as taxas transpiratórias, pois aumenta a diferença de pressão de vapor entre o ar e a folha, provocando transpiração mesmo com o ar saturado (HOPKINS, 1995; LUTTGE, 1997; SILVA JUNIOR, 2007).

Estudos em regiões de Cerrado, onde se registram, no período da seca, baixos valores de umidade relativa do ar, mostraram que a condutância estomática reduz, por conseguinte, as taxas de transpiração e de fotossíntese diminuem concomitantemente. Este efeito é também observado nas plantas, quando as temperaturas são baixas no inverno, e quando ocorrem os veranicos, durante a estação chuvosa (FRANCO, 2005; MORAES; PRADO, 1998; PEREZ; MORAES, 1983; PRADO et al., 2004).

Isso mostra que a grande maioria das espécies lenhosas do Cerrado regula fortemente a abertura estomática, mesmo na época chuvosa (depois de veranicos ou ao longo do dia, dependendo da demanda evaporativa da atmosfera), reduzindo, consideravelmente, sua taxa de assimilação de $\mathrm{CO}_{2}$ (FRANCO, 1998; FRANCO; LÜTTGE, 2002; MATTOS et al., 2002; MEINZER et al., 1999; NAVES-BARBIERO et al., 2000).

Outros estudos demonstraram que a transpiração decresce no meio do dia - período em que as temperaturas estão mais altas e a umidade relativa do ar é mais baixa (MORAES et al., 1989; PEREZ; MORAES, 1991a,b). Essa 'depressão do meio dia' é mais acentuada na estação seca, sendo a fotossíntese, a condutância estomática e a transpiração os processos mais afetados durante a seca. $\mathrm{Na}$ estação chuvosa, a alta umidade do ar contrabalanceia os menores valores de condutância estomática e os valores de transpiração não apresentando variações significativas ao longo do dia (MORAES; PRADO, 1998).

Este trabalho se propôs a relacionar as medidas de transpiração obtidas pelo "Transpirômetro de Equilíbrio" e do porômetro das espécies: Tabebuia serratifolia Nichols (Ipê amarelo), Hymenaea stigonocarpa Mart. Ex Hayne (Jatobá), Myroxilum balsamum Harms (Bálsamo), Eucalyptus camaldulensis Dehn e Eucalyptus citriodora Hook (eucaliptos).

\section{MATERIAL E MÉTODOS}

O experimento, instalado na casa de vegetação da Universidade Federal de Goiás, Instituto de Ciências Biológicas/ ICB1, consistiu de cinco tratamentos (espécies de plantas), com quatro repetições, durante o período de três meses, de agosto a outubro de 2006. O delineamento adotado foi inteiramente casualizado. Foram montados 21 transpirômetros, em 20 foram plantadas as espécies estudadas e suas repetições; e um transpirômetro permaneceu apenas com solo, para quantificar a evaporação de água pela sua superfície, ou testemunha.

O transpirômetro de equilíbrio construído consistiu de um reservatório, onde, diariamente era reabastecido com água. Esse reservatório era conectado a outro, intermediário, dotado de uma boia que controlava o nível de água em um terceiro reservatório, completo com solo, onde as mudas foram plantadas (Figura 1).

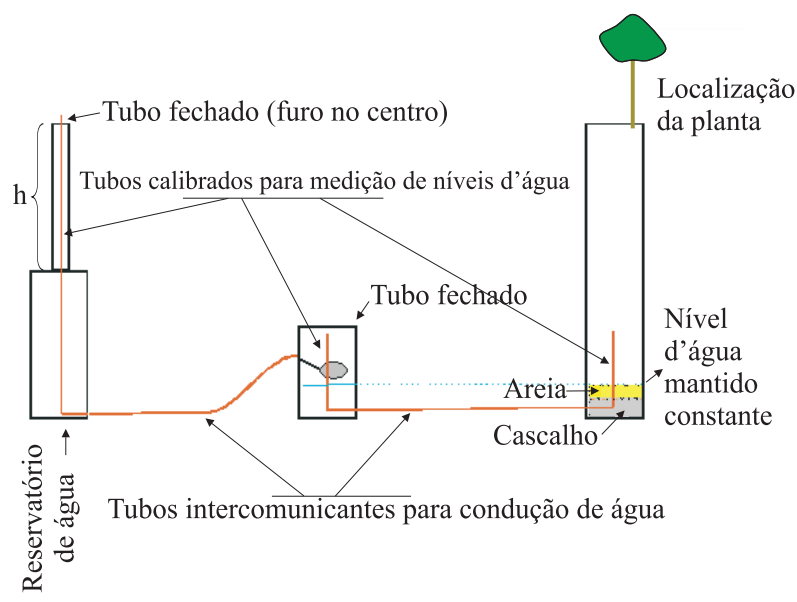

Figura 1 - Transpirômetro de estado de equilíbrio.

Figure 1 - Balance state transpirometer.

As seguintes variáveis foram medidas: meteorológicas (temperatura do ar, umidade relativa do ar, radiação fotossinteticamente ativa); transpiração da planta e transpiração foliar. As espécies florestais nativas Tabebuia serratifolia Nichols (ipê-amarelo), Hymenaea stigonocarpa Mart. Ex Hayne (jatobá), Myroxilum balsamum Harms

Cerne, Lavras, v. 17, n. 4, p. 509-515, out./dez. 2011 
(bálsamo) e as exóticas, Eucalyptus camaldulensis e Eucalyptus citriodora (eucaliptos) foram escolhidas para o trabalho, em razão da relevância socioeconômica e ambiental. Todas as mudas apresentavam entre $15 \mathrm{~cm}$ a 20 $\mathrm{cm}$ de altura quando plantadas, sendo que todas as espécies vieram acondicionadas em sacos de polietileno preto, com $9 \mathrm{~cm} \times 15 \mathrm{~cm}$, com $0,07 \mathrm{~mm}$ de espessura.

A transpiração da planta $(\mathrm{T})$, definida como a quantidade de água transpirada (volume) em um dado tempo $(\mathrm{t})$ por área foliar total de cada planta (AF), foi mensurada semanalmente (SUTCLIFFE, 1980). Inicialmente, mudas de mesmo tamanho das cinco espécies plantadas no vaso do transpirômetro foram levadas ao laboratório e com o medidor eletrônico de área foliar, modelo LI-3000 (LI-COR, Inc, Lincoln, NE, USA), estimaram-se as áreas foliares por espécie de planta, medindo-se simultaneamente comprimento e largura das folhas de cada espécie. Com os dados coletados, utilizouse o artifício de ajustar os dados, por regressão, usando o Programa Computacional para Ajuste de Equações em Dados Experimentais da CEPAGRI-Unicamp (1991).

Fizeram-se ajustes entre Área foliar x largura da folha (L), Área foliar x comprimento da folha (C) e Área foliar x produto (LxC). Das equações obtidas, escolheu-se para estimar as áreas foliares para cada espécie, àquela que apresentou a melhor correlação, pela análise do coeficiente de determinação $\left(r^{2}\right)$. Desse modo, a partir das equações obtidas, semanalmente foram tomadas as medidas de comprimento e largura das folhas e de cada folíolo, para cada planta, que substituídas na equação resultava na área foliar por espécie por repetição. Todas as medidas foram transformadas em $\mathrm{dm}^{2}$.

De posse do volume médio diário de água consumida por espécie, calculou-se o volume médio de água consumido semanalmente por cada espécie, pelo somatório dos volumes médios diários por planta. Posteriormente, com o uso das coletas semanais das médias das áreas foliares de cada espécie, resultados em $\mathrm{dm}^{2}$, calculou-se a transpiração da planta. Os resultados foram apresentados na unidade de medida de $\mu \mathrm{gdm}^{-2} \mathrm{~s}^{-1}$.

Com o aparelho porômetro de difusão de estado estacionário ("steady state") marca LICOR, modelo $1600 \mathrm{M}$, mensuraram-se, semanalmente, às $8 \mathrm{~h}, 11 \mathrm{~h}, 13 \mathrm{~h}$, $15 \mathrm{~h}, 17 \mathrm{~h}$ e $19 \mathrm{~h}$, a transpiração da folha (Tf), umidade relativa (UR) e radiação fotossinteticamente ativa (RFA) em folhas do terço mediano da árvore por cada repetição das cinco espécies estudadas.

Os dados foram coletados em folhas situadas no terço mediano da planta, escolhidas aleatoriamente.
Coletaram-se dados nos dias 22 de setembro, $01,05,13$ e 21 de outubro de 2006, transformados em Dias Julianos (DJ), respectivamente, 236, 272, 276, 284 e 292.

Foram realizadas medições nas faces abaxial (aba) e adaxial (ada) das folhas de eucalipto e dos folíolos das espécies nativas. A transpiração total da folha (Tf) foi resultado do somatório das medidas nas duas faces da folha, dada em $\mu \mathrm{gdm}^{-2} \mathrm{~s}^{-1}$.

As variáveis foram avaliadas a cada semana, ao longo de onze semanas, configurando experimento de parcelas subdivididas no tempo (split-plot in time).

Os resultados foram analisados pelo programa computacional STATISTICALANALYSIS SYSTEM (SAS INSTITUTE, 1990). Para efeito da análise, usou-se um nível de significância de 5\% para as variáveis analisadas.

\section{RESULTADOS E DISCUSSÃO}

Ao proceder-se a comparação dos resultados obtidos pelo transpirômetro e pelo porômetro, observaramse variações dos resultados de transpiração média ( $\mathrm{T}$ em $\left.\mu \mathrm{gdm}^{-2} \mathrm{~s}^{-1}\right)$, no período compreendido entre $9 \mathrm{~h}$ e $15 \mathrm{~h}$, para os dias julianos 263, 272, 276, 284 e 292 (Figuras 2 e 3).

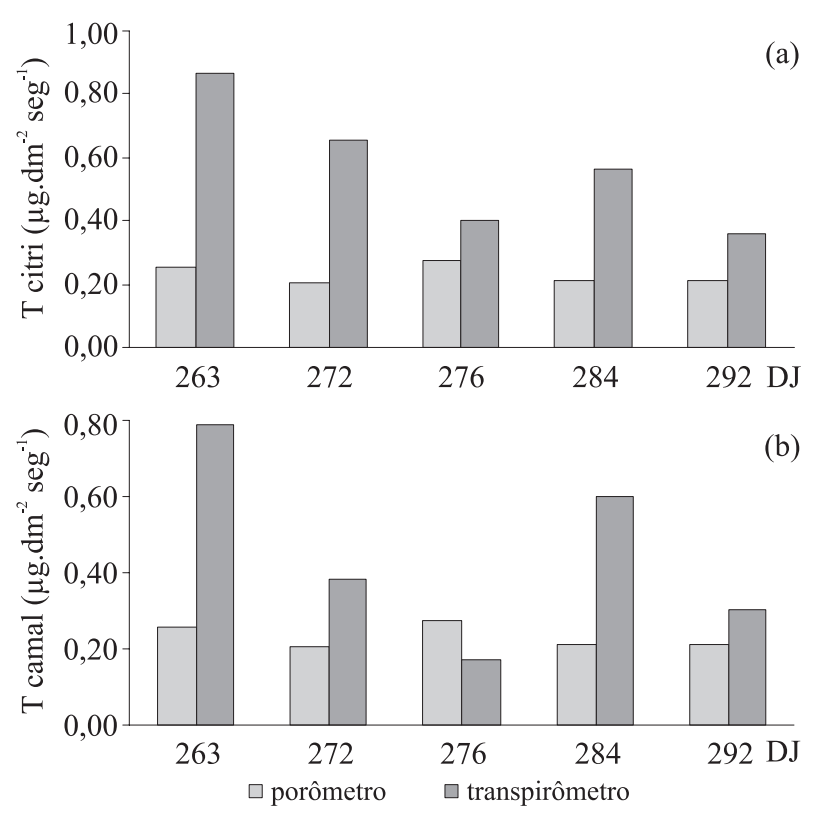

Figura 2 - Curvas de Transpiração (T) em $\mu \mathrm{gdm}^{-2} \mathrm{~s}^{-1}$ no período de $9 \mathrm{~h}$ a $15 \mathrm{~h}$ dos dias julianos 263, 272, 276, 284 e 292. a) Eucalyptus citriodora; b) E. camaldulensis.

Figure 2 - Transpiration Curves (T) in $\mu \mathrm{gdm}^{-2} \mathrm{~s}^{-1}$ for the period between 9am and 3pm on Julian days 263, 272, 276, 284 and 292. a) Eucalyptus citriodora; b) E. camaldulensis.

Cerne, Lavras, v. 17, n. 4, p. 509-515, out./dez. 2011 

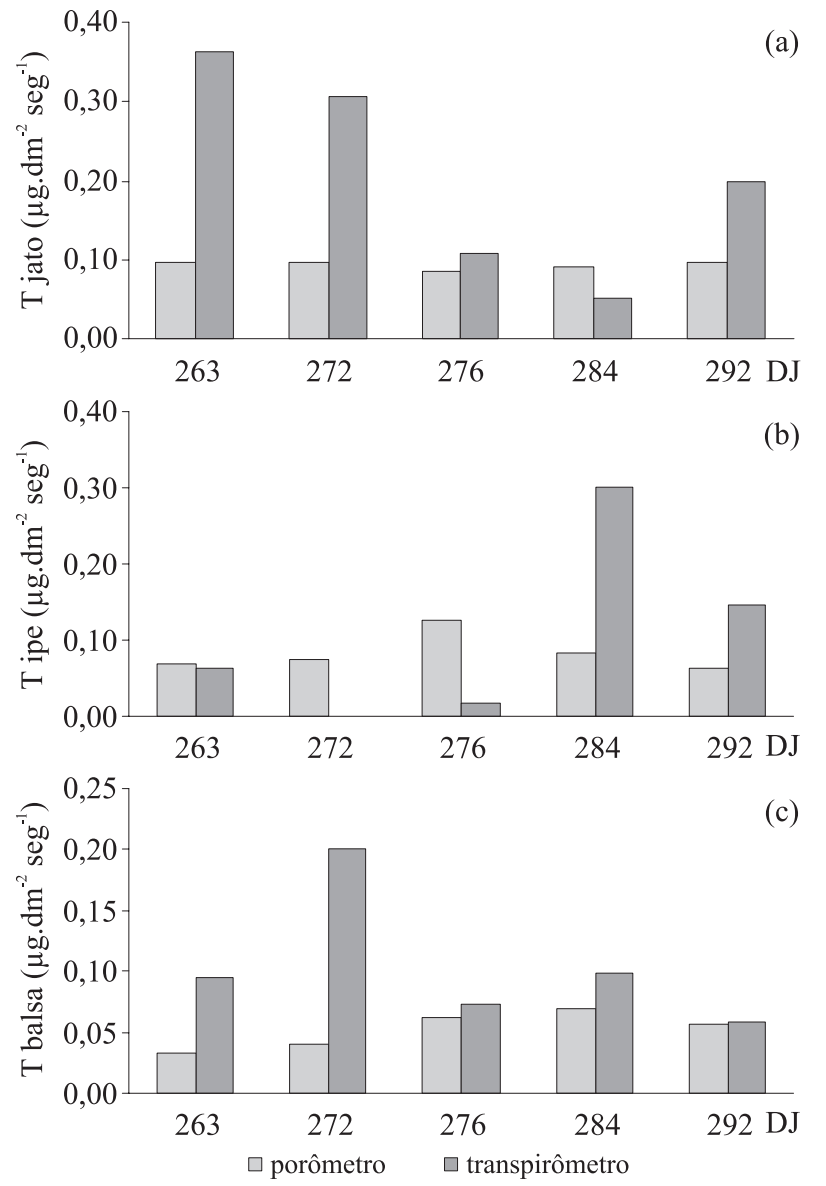

Figura 3 - Curvas de Transpiração (T) em $\mu \mathrm{gdm}^{-2} \mathrm{~s}^{-1}$, no período de 9 h às $15 \mathrm{~h}$, dos dias julianos 263, 272, 276, 284 e 292. a) jatobá; b) ipê; c) bálsamo.

Figure 3 - Transpiration Curves (T) in $\mu \mathrm{gdm}^{-2} \mathrm{~s}^{-1}$ for the period between 9am and 3pm on Julian days 263, 272, 276, 284 and 292. a) jatoba; b) ipe; c) balsamo.

Para Eucalyptus citriodora a maior transpiração média do período (9h-15h) ocorreu no DJ 263 , de 0,86 $\mu \mathrm{gdm}^{-2} \mathrm{~s}^{-1}$, valor 3,31 vezes maior do que o medido pelo porômetro $\left(0,26 \mu \mathrm{gdm}^{-2} \mathrm{~s}^{-1}\right)$ (Figura $2 \mathrm{a}$ ).

Os valores de $\mathrm{T}$ medidos no transpirômetro foram superiores aos do porômetro para as espécies de eucaliptos, em todos os dias do estudo (Figura 2), no entanto, para as nativas, o mesmo fato não ocorreu. Com as espécies jatobá e ipê, a T medida no transpirômetro foi menor do que o do porômetro, em, pelo menos, um dia. Quanto ao bálsamo, o valor de $\mathrm{T}$ foi semelhante em ambas as observações no DJ 292 (Figura 3 c).

Cerne, Lavras, v. 17, n. 4, p. 509-515, out./dez. 2011
$\mathrm{O}$ maior valor de $\mathrm{T}$ medido pelo porômetro, no DJ 276, foi de $0,27 \mu \mathrm{gdm}^{-2} \mathrm{~s}^{-1}$. Para E. camaldulensis observa-se comportamento semelhante ao citriodora, com os maiores valores de T, $0,79( \pm 0,0395) \mu \mathrm{gdm}^{-2} \mathrm{~s}^{-1}$, no mesmo dia (Figura $2 \mathrm{~b}$ ).

As espécies de eucaliptos não apresentaram diferença significativa das taxas transpiratórias no DJ $263(p=0,2021)$, embora tenham, ambos, diferenças significativas entre as nativas $(\mathrm{p}<0,001)$.

O jatobá obteve no transpirômetro, taxas maiores de $\mathrm{T}$, de $0,38( \pm 0,019)$ e $0,31( \pm 0,015) \mu \mathrm{gdm}^{-2} \mathrm{~s}^{-1}$, nos primeiros dias do estudo (Figura 3 a), muito embora, a transpiração mensurada pelo porômetro, tenha sido semelhante durante todos os dias $(\mathrm{p}<0,001)$.

Os valores médios de transpiração para o ipê foram maiores nos dias $284\left(0,30 \mu \mathrm{gdm}^{-2} \mathrm{~s}^{-1}\right)$ e $292\left(0,15 \mu \mathrm{gdm}^{-2} \mathrm{~s}^{-1}\right)$, pelo transpirômetro e, pelo porômetro, dias $276(0,13$ $\left.\mu \mathrm{gdm}^{-2} \mathrm{~s}^{-1}\right)$ e $284\left(0,08 \mu \mathrm{gdm}^{-2} \mathrm{~s}^{-1}\right)$. O bálsamo, nos dias 272 e 284, o transpirômetro, registrou valores de T maiores, enquanto que o porômetro, em 284, apresentou o maior $\mathrm{T}$ de $0,07 \mu \mathrm{gdm}^{-2} \mathrm{~s}^{-1}$.

Essas diferenças se justificam na medida em que o porômetro registra a transpiração instantânea por $\mathrm{cm}^{2} \mathrm{de}$ folha, quantificando-se uma média ponderada de $\mathrm{T}$ dos horários avaliados, subestimando, assim, os resultados. O transpirômetro quantifica a transpiração da planta toda durante o período, sendo, portanto, uma medida cumulativa, o que permite mensurar a quantidade real de água transpirada. Outra vantagem é o fato de que, além da transpiração foliar, esse equipamento permite avaliar a transpiração cuticular, lenticular e estomática (CONFORTO et al., 2005; SALISBURY; ROSS, 1992).

No entanto, em ambos os métodos de mensuração, observa-se que as maiores taxas transpiratórias ocorreram entre os DJ 263 e 284. O ipê apresentou pico de transpiração DJ 284, tanto no porômetro quanto no transpirômetro, justificado pela produção de novas folhas que interferem nas taxas transpiratórias.

E. camaldulensis e E. citriodora apresentaram curvas de transpiração semelhantes $(\mathrm{p}=0,8103)$ e levemente superiores a das espécies nativas, considerando significante a diferença $(\mathrm{p}<0,001)$, durante todo o experimento.

As espécies nativas, ipê, jatobá e bálsamo não apresentaram diferença significativa nas taxas transpiratórias, durante o experimento $(\mathrm{p}<0,001)$ ao nível de $5 \%$ e significância. 
Durante o experimento, todas as espécies transpiraram mais nas primeiras semanas, nos meses de agosto-setembro, tendendo a diminuir a transpiração, de forma linear, nas últimas semanas do experimento, quando a UR esteve mais alta (média em outubro de $90 \%$ ) e as temperaturas do ar na casa de vegetação, mais amenas. À exceção do ipê, todas as quatro apresentaram taxas médias transpiratórias elevadas nas semanas iniciais do plantio, quando se registraram baixas umidades do ar e temperaturas elevadas.

A idade da folha interfere na transpiração e condutância estomática. Seus resultados mostraram que a abertura estomática foi muito maior no terceiro par de folhas que em qualquer outro par. No par mais jovem, a abertura foi menor que um terço do valor obtido no terceiro par; e, em qualquer folha, a resistência ao fluxo de ar aumentou da base para o ápice, aparentemente indicando uma maior abertura estomática próxima à base da folha, portanto, ocasionando maiores taxas transpiratórias. Esse resultado é justificado, uma vez que, as folhas intermediárias estão completamente estendidas, apresentando maiores áreas foliares. As folhas da base, mais maduras, senescentes, com estômatos mais susceptíveis a situações de estresse (ALVIM, 1968; MARIANO et al., 2009; MEINZER et al., 1993).

Larcher (2000) discorre que a posição das folhas na copa das árvores determina as adaptações morfológicas foliares, como aumento/diminuição do número de estômatos, o que para a transpiração interfere significativamente.

Nesse sentido, ao avaliar-se os resultados do transpirômetro, tem-se a transpiração total da planta no período. Contudo, ao se utilizar dados porométricos, os valores de $\mathrm{T}$ representam fidedignamente às variações ao longo do dia, podendo-se constatar a regulação da transpiração em função das variáveis micrometeorológicas por hora, o que permite correlacionar quais fatores interferem nas variações de $T$, uma vez que a transpiração não é constante por todo o período.

Quando a água não é fator limitante, há uma regulação temporal das aberturas estomáticas, por conseguinte, interferindo na transpiração, com taxas diferentes ao longo do dia, em resposta às oscilações de umidade relativa, temperatura e luminosidade em cada hora do dia (NAVES-BARBIERO et al., 2000; TAIZ; ZEIGER, 2004).

Isso foi observado no DJ 292 (Figura 4), quando a transpiração das cinco espécies variou durante o dia. $E$. camaldulensis, E. citriodora e bálsamo transpiraram mais às $11 \mathrm{~h}\left(0,43 \mu \mathrm{gdm}^{-2} \mathrm{~s}^{-1}, 0,32 \mu \mathrm{gdm}^{-2} \mathrm{~s}^{-1}\right.$ e $0,27 \mu \mathrm{gdm}^{-2} \mathrm{~s}^{-1}$,

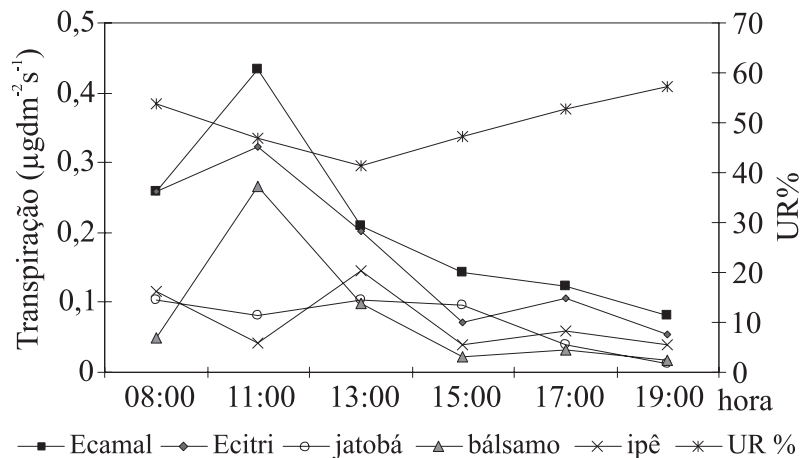

Figura 4 - Curso diário da transpiração das cinco espécies no DJ 292.

Figure 4 - Daily transpiration pattern for the five species on JD 292.

respectivamente), enquanto que o jatobá apresentou a maior taxa às $13 \mathrm{~h}\left(0,10 \mu \mathrm{gdm}^{-2} \mathrm{~s}^{-1}\right)$. $\mathrm{O}$ ipê transpirou mais às $8 \mathrm{~h}$, computando $0,12 \mu \mathrm{gdm}^{-2} \mathrm{~s}^{-1}$.

Mas, ambos os equipamentos registraram as variações de transpiração no período de maior demanda evaporativa atmosférica, quando se verificaram altas temperaturas e RAF. No entanto, com baixa umidade relativa do ar, a taxa transpiratória foi alta para todas as espécies estudadas, à exceção do ipê que é uma espécie caducifólia e, nesse período, não tinha folhas.

$\mathrm{O}$ aumento da transpiração (Figuras 2 e 3) parece estar relacionado à maior abertura estomática, ocasionada pelo aumento de DPV que, mesmo causando fechamento parcial dos estômatos, mantém a taxa de transpiração elevada.

Angelocci et al. (2004), afirmam que a abertura estomática é dependente do estado hídrico da folha e da demanda evaporativa da atmosfera (DPV).

Esses resultados estão de acordo com Nogueira e Silva (2002) que, estudando resistência estomática, tensão de água no xilema e teor de clorofila em genótipos de gravioleira, observaram que, de modo geral, os valores da $\mathrm{T}$ foram mais elevados em setembro do que em dezembro, quando a demanda evaporativa atmosférica esteve maior do que no último mês.

Vários estudos têm demonstrado uma boa relação entre resistência estomática e o déficit de saturação de vapor de água do ar (MACHADO et al., 2002). Schulze et al. (1972) consideram que a baixa umidade do ar atua no fechamento estomático e, por sua vez, a alta umidade conduz à abertura, sendo que os estômatos funcionam como o principal sensor de umidade.

Cerne, Lavras, v. 17, n. 4, p. 509-515, out./dez. 2011 


\section{CONCLUSÕES}

Embora seja o porômetro um aparelho de grande precisão, ele proporciona resultados instantâneos, podendo não refletir resultados reais apresentados pelas plantas ao longo de certo período. Ao utilizar-se o porômetro, evidenciou-se que todas as espécies estudadas modularam as taxas transpiratórias, conforme a umidade relativa do ar, radiação luminosa e ainda, variações nas temperaturas durante o período do dia, em casa de vegetação.

O transpirômetro mediu diferentes respostas de transpiração para as espécies estudadas em clima de Cerrado. As exóticas exibem, de modo geral, maior transpiração, indicando maior consumo de água, ao contrário das espécies nativas, que transpiram e consumem menos água do que os eucaliptos. Em média, ao longo das 11 semanas, os eucaliptos transpiram 12 vezes mais do que bálsamo, sete a mais do que o ipê e seis vezes a transpiração do jatobá.

\section{REFERÊNCIAS}

ALVIM, P. T. Some factors to be considered in diagnosing moisture deficiency by stomatal opening. Ciência e Cultura, São Paulo, v. 20, n. 4, p. 726-732, 1968.

ANGELOCCI, L. R.; MARIN, F. R.; OLIVEIRA, R. F.; RIGHI, E. Z. Transpiration, leaf diffusive conductance, and atmospheric water demand relationship in an irrigated acid lime orchard. Brazilian Journal of Plant Physiology, Rio de Janeiro, v. 16, p. 53-64, 2004.

CONFORTO, E. C.; CAVALCANTE, J. R.; PESSOA, J. D. C.; MORENO, R. M. B.; MATTOSO, L. H. C. Seasonal variations of gas exchange, relative trunk turgescence and yield in two clones of rubber tree cultivated in Votuporanga, SP, Brazil. Acta Botanica Brasilica, São Paulo, v. 19, n. 4, p. 733-740, 2005.

FRANCO, A. C. Biodiversidade de forma e função: implicações ecofisiológicas das estratégias de utilização de água e luz em plantas lenhosas do Cerrado. In: SCARIOT, A.; FELFILI, J. M.; SOUSA-SILVA, J. C. (Ed.). Cerrado: ecologia, biodiversidade e conservação. Brasília: Ministério de Meio Ambiente, 2005. p. 179-196.

FRANCO, A. C. Seasonal patterns of gas exchange, water relations and growth of Roupala montana, an evergreen savanna species. Plant Ecology, Oxford, v. 136, p. 69-76, 1998.
FRANCO, A. C.; LÜTTGE, U. Midday depression in savanna trees: coordinated adjustments in photochemical, efficiency, photorespiration, $\mathrm{CO}_{2}$ assimilation and water use efficiency. Oecologia Brasiliensis, Rio de Janeiro, v. 131, p. 356-365, 2002 .

HOPKINS, W. G. Introduction to plant physiology. 2. ed. New York: J. Wiley, 1995. 512 p.

LARCHER, W. Ecofisiologia vegetal. São Carlos: Rima, 2000. 531 p.

LUTTGE, U. Interaction of stress factores and the middaydepression in plants with C3: photosynthesis. Physiological Ecology of Tropical Plants, New York, v. 35, p. 122-124, 1997.

MACHADO, E. C.; MEDINA, C. L.; GOMES, M. M. A.; HABERMANN, G. Variação sazonal da fotossíntese, condutância estomática e potencial da água na folha de laranjeira 'Valência'. Scientia Agricola, Piracicaba, v. 59, n. $1,2002$.

MARIANO, K. R.; BARRETO, L. S.; SILVA, A. H. B.; NEIVA, G. K. P.; AMORIM, S. Fotossíntese e tolerância protoplasmática foliar em Myracrodruon urundeuva fr. All. submetida ao déficit hídrico. Caatinga, Mossoró, v. 22, n. 1, p. 72-77, 2009.

MATTOS, E. A.; LOBO, P. C.; JOLY, C. A. Overnigth rainfall inducing rapid changes in photosynthetic behaviour in a Cerrado woody species during a dry spell amidst the rainy season.

Australian Journal of Botany, Melbourne, v. 50, p. 1-6, 2002.

MEINZER, F. C.; GOLDSTEIN, G.; FRANCO, A. C.; BUSTAMANTE, M.; IGLER, E.; JACKSON, P.; CALDAS, L.; RUNDEL, P. W. Atmospheric and hydraulic limitations on transpiration in Brazilian Cerrado woody species. Functional Ecolcology, London, v. 13, p. 273-282, 1999.

MEINZER, F. C.; GOLDSTEIN, G.; HOLBROOK, N. M.; JACKSON, P.; CAVELIER, J. Stomatal and environmental control of transpiration in a lowland tropical forest tree. Plant, Cell \& Environment, Oxford, v. 16, p. 429-436, 1993.

MORAES, J. A. P. V.; PEREZ, S. C. J. G. A.; CARVALHO JÚNIOR, L. F. Curso diário e sazonal do potencial da água e da resistência estomática em plantas de um cerradão. Annals of the Missouri Botanical Garden, Saint Louis, v. 27, p. 13-23, 1989.

Cerne, Lavras, v. 17, n. 4, p. 509-515, out./dez. 2011 
MORAES, J. A. P. V.; PRADO, C. H. B. A. Photosynthesis and water relations in Cerrado vegetation. Oecologia Brasiliensis, Rio de Janeiro, v. 4, p. 45-63, 1998.

NAVES-BARBIERO, C. C.; FRANCO, A. C.; BUCCI, S. J.; GOLDSTEIN, G. Fluxo de seiva e condutância estomática de duas espécies lenhosas sempre-verdes no campo sujo e cerradão. Revista Brasileira de Fisiologia Vegetal, Campinas, v. 12, p. 119-134, 2000.

NOGUEIRA, R. J. M. C.; SILVA, E. C. Comportamento estomático em plantas jovens de Schinopsis brasiliensis Engl. cultivadas sob estresse hídrico. Iheringia, Série Botânica, Porto Alegre, v. 57, n. 1, p. 31-38, 2002.

PENTEADO, M. B. Evolução de um programa universidadeempresa de pesquisa florestal cooperativa. 2004. $109 \mathrm{f}$. Dissertação (Mestrado em Recursos Florestais) - Escola Superior de Agricultura “Luiz de Queiroz”, Piracicaba, 2004.

PEREZ, S. C. J. G. A.; MORAES, J. A. P. V. Curso diário e sazonal do potencial da água e da condutância estomática em espécies de cerradão. Revista Brasileira de Biologia, São Carlos, v. 51, n. 4, p. 805-811, 1991a.

PEREZ, S. C. J. G. A.; MORAES, J. A. P. V. Determinações de potencial hídrico, condutância estomática e potencial osmótico em espécies dos estratos arbóreo, arbustivo e herbáceo de um cerradão. Revista Brasileira de Fisiologia Vegetal, Campinas, v. 3, n. 1, p. 27-37, $1991 \mathrm{~b}$.

PEREZ, S. C. J. G. A.; MORAES, J. A. P. V. Efeito da geada sobre as relações hídricas em plantas do Cerrado. In: SEMINÁRIO REGIONAL DE ECOLOGIA, 3., 1983, São Carlos. Anais... São Carlos: UFSCar, 1983. p. 277-283.
PRADO, C. H. G. A.; WENHUI, Z.; ROJAS, M. H. C.; SOUZA, G. M. Seasonal leaf gas exchange and water potential in a woody Cerrado species community. Brazilian Journal of Plant Physiology, Londrina, v. 16, n. 1, p. 7-16, 2004.

RODRIGUEZ, L. C. E.; SEIXAS, F.; SILVA-JUNIOR, F. G.; GONÇALVES, J. L. M.; STAPE, J. L.; LIMA, J. O. B. P.; AMARAL, W. A. N.; FREITAS, A. R. H. R. Ciência e tecnologia no setor florestal brasileiro: diagnóstico, prioridades e modelos de financiamento: relatório final. Piracicaba: Ministério da Ciência e Tecnologia, 2002. 12 p.

SALISBURY, F. B.; ROSS, C. W. Plant physiology. 4. ed. Belmont: Wadsworth, 1992. 682 p.

SAS INSTITUTE. SAS/STAT: guide version 6. 3. ed. Cary, 1990.

SCHULZE, E. D.; LANGE, O. L.; BUSCHBOM, H.; KAPPEN, L.; EVENARI, M. Stomatal responses to changes in humidity in plants growing in the desert. Planta, Berlin, v. 108, p. 259-270, 1972.

SILVA JÚNIOR, G. S. Respostas biométricas, ecofisiológicas e nutricionais em genótipos diplóides de bananeira (Musa spp) submetidos à salinidade. 2007. $106 \mathrm{f}$. Tese (Doutorado em Botânica) - Universidade Federal Rural de Pernambuco, Recife, 2007.

SUTCLIFFE, J. F. As plantas e a água. São Paulo: Edusp, 1980. $67 \mathrm{p}$.

TAIZ, L.; ZEIGER, E. Fisiologia vegetal. 3. ed. Porto Alegre: Artmed, 2004. 719 p.

Cerne, Lavras, v. 17, n. 4, p. 509-515, out./dez. 2011 
